\section{LA MUJER NEGRA PERIFÉRICA EN LA LITERATURA}

\section{BRASILENA CONTEMPORANEA}

PERIPHERAL BLACK WOMAN IN BRASILIAN CONTEMPORARY LITERATURE

Lucía Tennina

Universidad de Buenos Aires

\section{Resumen:}

ABSTRACT:

En este artículo analizaremos la This article explores the problematic that problematización que tres escritoras three contemporary writers self-identified as contemporáneas auto-identificadas dentro part of the Marginal-Periphery Literature's del Movimiento de Literatura Marginal Movement from São Paulo's city install on the Periférica de la ciudad de San Pablo instalan peripheral issue of identity and on socially Pobre la cuestion de la identidad periférica periptracted representations of the focially por un cuentine por un lado, y sobre las representaciones in periphery, through the revision of certain forjadas socialmente sobre lo femenino en la configurations of the feminine and self lyrics periferia, por otro, a través de la revisión de configurations.

ciertas figuraciones del ser femenino y de las

figuraciones del yo de cada una de ellas.

Palabras claves:

\section{KEY WORD:}

Marginal literature, periphery, São Paulo, women.

Literatura marginal, periferia, São Paulo, mujer.
Hace ya más de una década que el campo literario brasileño viene siendo tensionado por una serie de escritores que optaron por autodenominarse (o circulan por espacios que se autoidentifican como) parte de un "movimiento de literatura marginal". En estos casos el mote no proviene solamente de las prácticas literarias no institucionalizadas, como sucedió con los "poetas marginales" de los años '70, sino del origen social de los que firman los cuentos y poemas. Aquellos que por vivir en las zonas pobres son señalados como "marginales" por el sentido común, desplazan esa palabra del campo de lo social a lo literario y comienzan a identificar de esa manera sus propias producciones escritas.

La autodenominada literatura marginal-periférica de la ciudad de San Pablo se instala con fuerza a partir de la publicación de relatos que pretenden resignificar el ser periférico otorgándole autoestima y construyendo una identidad. Pero detrás de esa idea general de lo periférico, se esconden una variedad de condiciones de exclusión: ser negro-periférico, ser nordestino-periférico, ser mujer-periférica, ser mujer-negraperiférica. Se trata de una serie de identidades que no responden al habitus del hombre o de la mujer de la clase media de la ciudad. Dentro de esta serie, un grupo clave que viene abriéndose espacio en la literatura marginal-periférica son las mujeres pobres y mayormente negras. La particularidad de este conjunto se encuentra en que ellas no solamente sufren la exclusión de clase, sino también la de género, y ese sufrimiento es provocado tanto por los grupos hegemónicos como por los mismos hombres periféricos. Serían algo así como subalternas de los subalternos, dominadas de los dominados. Es a partir de esa doble exclusión que las mujeres escritoras de la literatura marginalperiférica articulan sus discursos. "Elas tiveram que criar uma espécie de movimento dentro do movimento", dice Érica Peçanha do Nascimento, antropóloga pionera en estudiar el Movimiento de literatura marginal-periférica ${ }^{1}$.

El trabajo que fue fraguando la llamada literatura marginal-periférica está marcado por una mayor presencia masculina -en consonancia con el campo literario letrado. Ya desde la primera publicación que le dio el nombre al conjunto puede percibirse una supremacía de escritores hombres: de los 48 autores que conforman los tres números de los números especiales de la Revista Caros Amigos/ Literatura Marginal², solamente

1 Hablamos de literatura marginal-periférica haciendo uso del concepto acuñado por Érica Peçanha do Nacimento: "Literatura Marginal" foi a primeira categoria que os próprios escritores das regiões suburbanas da Cidade de São Paulo usaram para identificar seus textos. Posteriormente, alguns escritores começaram a optar pela categoria "literatura periférica". Erica Peçanha do Nascimento en una entrevista com Ingrid Hapke explica este cambio: "Entendo que a junção dos termos "literatura" e "marginal" produziu uma expressão polissêmica e, portanto, falha como categoria explicativa se não estiver contextualizada" (Hapke, 2011: 222). Por esta variedad en la forma de nombrar las producciones esta antropóloga opta por "literatura marginal-periférica".

2 En el año 2001 el escritor Ferréz idea y se encarga de organizar una edición especial de la revista Caros Amigos, con publicaciones de textos de escritores moradores principalmente de las regiones suburbanas de San Pablo (con la excepción de dos cariocas, Paulo Lins y Edson Veóca, oriundos 
9 son mujeres. Asimismo, de los 11 títulos que tiene la Editorial Toró $\underline{3}$-la primera editorial gestionada íntegramente por un escritor periférico- hay solamente 3 firmados por mujeres, dos de ellos en coautoría con hombres. De las 72 publicaciones de literatura marginal-periférica catalogadas hasta el 2011, Érica Peçanha do Nascimento, 12 son mujeres, 4 de ellas en coautoría (Peçanha do Nascimento, 2011: 104). Si se toman en cuenta las antologías lanzadas desde el comienzo del Movimiento hasta ahora, en todas puede percibirse la significativa desproporción entre hombres y mujeres participando de ellas. Este predominio masculino se evidencia también en los saraus ${ }^{4}$ de poesía de las periferias: son los hombres quienes suelen estar en la creación y conducción de esos espacios, siendo que las mujeres funcionan como "primeras damas" (Peçanha do Nascimento, 2011: 91) colaborando enormemente para el funcionamiento del sarau.

Pese a la desproporción de publicaciones firmadas por hombres frente a las de las mujeres cabe mencionar que año a año las firmadas por mujeres periféricas van creciendo, tal y como señala Érica Peçanha do Nascimento: “Nestes anos de observação pude notar que a presença das mulheres continua sendo menor do que a dos homens, mas tem sido crescente a participação delas" (Peçanha do Nascimento, 2011: 22).

En este artículo centraremos nuestra atención en tres nombres de poetas periféricas, cuya condición de pioneras en diversas prácticas nos lleva a reunirlas: Elizandra Souza con "Punga" (2007) y "Águas da cabaça" (2013), Raquel Almeida con "Sobrevivendo no gueto" (2008) y Dinha con “De passagem e não de passeio" (2008). Elizandra Souza participa del Sarau da Cooperifa casi desde sus inicios y participó del tercer número especial de la Revista Caros Amigos/Literatura Marginal que dio inicio al Movimiento. Dinha es la primera poeta mujer periférica que publicó en el año 2008 un libro de

ambos de Cidade de Deus, una gran favela localizada en la zona oeste de dicha ciudad). El nombre que Ferréz eligió para tal dición especial, que tendría dos números más (2002 y 2004) fue “Literatura Marginal", inaugurando así un universo en el campo de la "literatura" y de la "cultura periférica". Tanto los críticos literarios como los mismos "escritores marginales", concuerdan en señalar a estos números especiales como inicio de una fase nueva en relación con la literatura de los sectores de trayectoria no letrada.

3 Edições Toró es una colectivo ideado por Allan da Rosa y Mateus Subverso, nacido en 2005 “en el patio trasero de una casilla del Municipio de Taboão da Serra”, según cuentan los mismos editores. La propuesta de la editorial es afirmar y publicar una literatura que se articula más allá de la palabra escrita, por lo que publican libros de poetas que suelen declamar en saraus da periferia de San Pablo o de escritores vinculados al RAP. Cada una de las publicaciones, a través de una caligrafía específica para cada libro, de dibujos y diseños, de tapas conceptuales, de uso de colores en algunos casos, pretende evocar el cuerpo, la voz, la boca, la mirada que hace a esa literatura. Hasta el momento Edições Toró lanzó veinte libros. La Editorial desde hace cuatro años abrió, asimismo, un espacio de arte-educación, que se ocupa de organizar cursos y seminarios vinculados a la cuestión afrobrasileña.

4 Los saraus de las periferias podrían definirse rápidamente como reuniones en bares de diferentes barrios suburbanos de la Ciudad de São Paulo donde los vecinos declaman o leen textos propios o ajenos frente a un micrófono, durante aproximadamente dos horas. Muchos bares -espacios donde suelen ocurrir los actos que luego se vuelven estadísticas (los asesinatos y el alcoholismo)-, funcionan desde entonces también como centros culturales (Tennina, 2014). poemas en una editorial comercial, Global Editora, en la colección Literatura Periférica (que también publicó libros de Allan da Rosa, Alessandro Buzo, Sérgio Vaz y Sacolinha, todos hombres). Raquel Almeida entró a la escena en el año 2007, cuando participó de la Antología Cadernos Negros Vol. 30 (Quilomhoje, 2007) y al año siguiente comenzó a co-organizar el Sarau Elo da Corrente, siendo la primera mujer que comparte la idealización de un sarau en la periferia.

Analizaremos aquí la problematización que estas tres escritoras instalan sobre la cuestión de la identidad periférica, por un lado, y sobre las representaciones forjadas socialmente sobre lo femenino en la periferia, por otro, a través de la revisión de ciertas figuraciones del ser femenino y de las figuraciones del yo de cada una de ellas. Si en la literatura escrita por hombres la mujer negra periférica aparece mitologizada, tanto positiva como negativamente, al punto de la abstracción, en estos textos escritos por mujeres estas figuraciones mitológicas se admiten de manera activa: leyéndolos a contrapelo, rearticulándolos creativamente, invirtiéndolos drásticamente.

Los textos que proponemos abordan los problemas de autorrepresentación marcados por el género, la etnia y la condición social. No pretendemos esbozar aqui una representación esencialista de la diferencia femenina periférica ni plantear que el deseo de ocupar un espacio diferente desde donde ser y escribir sea exclusivo de la escritura de la mujer de la periferia. Nos interesa reflexionar, más bien, sobre qué formas toma ese deseo en ese contexto e intentar percibir cómo se inscriben esa dislocación y esa diferencia en los textos elegidos, desafiando estereotipos culturales afincados.

\section{Revisión de estereotipos}

Muchas de las figuraciones del yo de estas escritoras asumen de manera activa los tradicionales íconos femeninos a través de diferentes decisiones retóricas que definen, a su vez, el estilo de cada una de ellas. Uno de los mitos $^{5}$.más fuertemente cuestionados en estas escritoras es de la mujer negra vista como un objeto de un erotismo y de una sensualidad exacerbadas de acuerdo con las representaciones articuladas desde una perspectiva eurocéntrica. El poema "Preservando herenças", de Elizandra Souza, por ejemplo, lo hace a partir de la explicación de las partes de su cuerpo y su vestimenta desde un punto de vista cultural e histórico:

As argolas em volta do pescoço

São para sustentar a exuberância do meu sorriso

Os tecidos que uso na cabeça

Demostram a sabedoria da minha ancestralidade

Os vestidos que moldam meu corpo

Dignificam o meu instrumento de existir

5 Nos manejamos con la nocion de "mito" que desarrolla Roland Barthes, esto es, los mitos expresan una visión del hombre y del mundo, una organización del cosmos y de la sociedad (Barthes, 2009). 
As argolas, os tecidos e os vestidos

Mais do que acessórios

São heranças que me ajudam a persistir. (Souza, 2013: 37)

Los elementos que enumera este poema desplazan su vínculo morfológico de símbolos asociados al erotismo del cuerpo-objeto de las mujeres (los vestidos apretados, los collares) hacia sus aspectos ancestrales, de esa manera esos símbolos se historizan y temporalizan, haciendo del cuerpo una identidad cultural, esto es, tal y como lo entiende Stuart Hall (2011), un cuerpo cargado de aspectos identitarios que surgen de la pertenencia a una cultura étnica, racial, lingüística, religiosa y de género. Haciendo uso del recurso de la sinécdoque, el poema de Elizandra Souza incorpora en su representación elementos de una tradición popular desvalorizada como manera de escapar a esa opresión: la memoria de la mujer negra, su vestimenta y sus rasgos se toman aquí como capitales simbólicos que obstruyen su aculturación y alimentan su rebelión. Este tipo de operaciones consisten en una resignificación que subraya el universo afectivo de esos elementos afirmando la perspectiva social negra desde la cual se escribe en tanto se afirman como conocimientos derivados de la experiencia.

El ícono de belleza femenina asociado a los parámetros representacionales blancos también es otra de las figuraciones a las que estas poetas responden de manera activa. Muchos de los poemas de Raquel Almeida suelen problematizar este esquema. "Meu cabelo", por ejemplo, desliga la idea de "belleza" del universo de la estética y la asocia al universo del origen y de la resistencia:

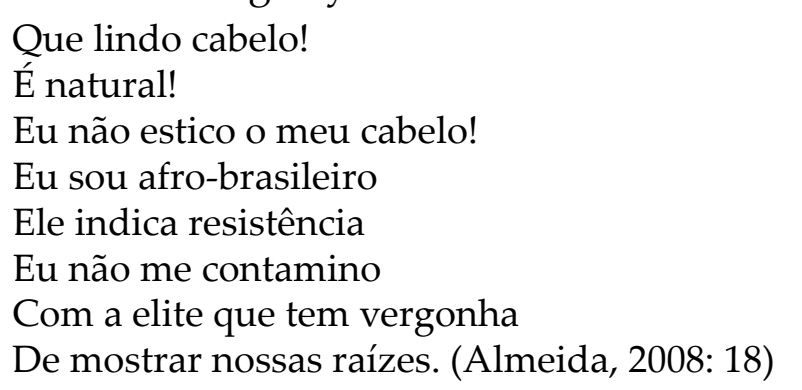

Como señala Pierre Bourdieu, "la probabilidad de sentirse incómodo en el cuerpo de uno [...], el malestar, la timidez o la vergüenza son tanto más fuertes en la medida en que es mayor la desproporción entre el cuerpo socialmente exigido y la relación práctica con el cuerpo que imponen las miradas y reacciones de los demás" (Bourdieu, 2000: 85). Es esa incomodidad a la que refiere Bourdieu es la que Raquel Almeida desarma en este poema: el esquema de belleza del hombre blanco se muestra como débil y artificial frente al poder ancestral del cabello de la mujer negra.

Otro de los íconos femeninos que estas escritoras vienen a responder tiene que ver con la función reproductiva. Las referencias a esta temática en todos los casos distan de celebrar la maternidad, que responde al mismo esquema que el de la mujer contemplada como objeto, esto es, la idea de un cuerpo-para-otro (Bourdieu, 2000: 83). El poema "MenstruAção", de Elizandra Souza, por ejemplo, propone el acto del sangrado mes a mes como una acción de rebeldía frente a todos los sangrados se han causado sobre las mujeres:

Sangre mais uma vez!

Expele do teu corpo

o embrião não fecundado

Junte todo o amargor

e sangre outra vez

[...]

Sangre nessa hipócrita sociedade

junte todas as dores expelidas,

retire a calcinha

esse absorvente encharquecid

E jogue fora todos esses sangrados.

Mas Menstrue e Ação! (Souza, 2007: 10)

La referencia al cuerpo de la mujer en este poema se propone como una respuesta al discurso típico de ciertos poetas hombres alrededor de la mujer, donde se las piensa fragmentadas en partes deseables (su pelo, sus ojos, sus pies, sus labios) o se las admira a la distancia, discurso que responde a los principios androcéntricos de visión que, como señala Bourideu, dispone que hay partes mostrables y partes no mostrables: “El cuerpo tiene [...] sus partes públicas, cara, frente, ojo, bigote, boca, órganos nobles de presentación de uno mismo en los que se condensa la identidad social, el pundonor, el nif, que impone enfrentarse y mirar a los demás a la cara, y sus partes privadas, ocultas o vergonzosas, que el decoro obliga a disimular" (Bordieu, 2000: 30). Este poema desarma esa dominación corporal transgrediendo los márgenes de su representación hace aparecer lo abyecto de su cuerpo. Tal y como lo entiende Julia Kristeva, lo abyecto se caracteriza por generar al mismo tiempo rechazo y atracción. Efectivamente aqui a menstruación es presentada sin eufemismos "encharcando" el absorbente, pero al mismo tiempo se propone como un acto de protesta, como un desestabilizador de estructuras: "No es la ausencia de limpieza o de la salud lo que vuelve abyecto, sino aquello que perturba una identidad, un sistema, un orden. Aquello que no respeta los límites, los lugares, las reglas" (Kristeva, 2006: 11).

La referencia a la idea de "reproducción" también aparece en Dinha y tampoco está ligada a la celebración de la reproducción femenina, sino que se asocia a las terribles condiciones de vida, a la idea de reproducción de las estadísticas que es un tema repetido en algunos de sus poemas. "De aquí de dentro da guerra" dice, por ejemplo:

De aqui de dentro da guerra,

não tem DIU nem camisinha

que te proteja da estúpida reprodução

da fome, da miséria, da ínfima estrutura. (Dinha, 2008:49)

La "guerra" a la que refiere Dinha en este poema la entiende como una guerra cotidiana, un guerra que al igual que un niño, "de pequeña foi crescendo, pulando os muros dos guetos, se alongando" (Dinha, 2008: 48). Así, a la vez que no se celebra la 
función reproductiva de la mujer, tampoco hay referencias bucólicas a la idea de niñez, sino una alegoría macabra.

La temática de la niñez presenta en estas poetas un lugar destacado. Junto con la necesidad de resignificar la representación de la mujer periférica, hay una intención de darle una historia a esa representación a partir de la referencia a la niñez de las mujeres negras y periféricas. Cuando se aborda este tema, lo que estos poemas muestran parece ser el contrarrelato de las historias infantiles tradicionales: están marcadas por un sufrimiento sin final feliz. Un disparador del sufrimiento suele estar nuevamente en los cabellos crespos, que son motivo de burlas o de discriminación, según puede leerse en "Menina Princesa", de Raquel Almeida:

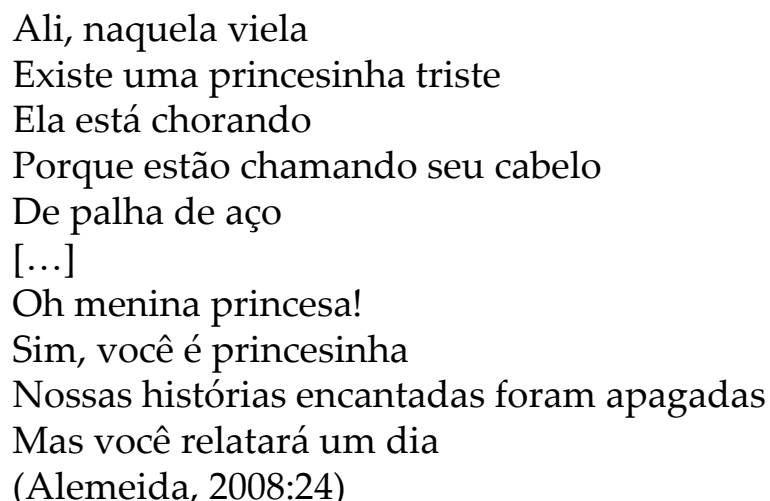

En el poema recién citado puede leerse cómo queda asociada la discriminación de una niña negra por parte de su entorno con los modelos culturales que reproducen las historias infantiles. En éstas, las princesas suelen ser de cabello lacio y generalmente rubias (pensemos, por ejemplo, en el nombre Blanca Nieves), de acuerdo con el parámetro de belleza eurocéntrico.

La lectura a contrapelo de determinadas historias tradicionales que podemos percibir en el poema de Raquel Almeida, también está presente en los textos de Dinha. Hay, en algunos momentos de su escritura, cierta ironía respecto del lirismo sentimental que suelen asociarse a la literatura femenina, herencia de los modos de figuración pública de las mujeres desde el siglo XIX que, sabemos, solo podían ser pensados como poetas líricas (las llamadas poetizas) o maestras. Un ejemplo en este sentido es el “Poeminha irônico", que cierra de esta manera:

$$
\begin{aligned}
& \text { Porque com você o meu mundo é perfeito. } \\
& \text { Pensando bem } \\
& \text { Melhor te deixar de lado. } \\
& \text { O perfeito é muito } \\
& \text { Chato. (Dinha, 2008:70) }
\end{aligned}
$$

El poema recién citado juega con el sentimentalismo de cierta escritura femenina que considera al otro masculino como viniendo a completar al yo lírico y que para expresarlo hace uso de adjetivos abstractos e indefinibles como el de "perfecto". El recurso en juego para llevar a cabo esta operación es la ironía, anticipada por el uso del blanco entre estrofa y estrofa que adelanta el giro respecto del tono que toma el final del poema, giro ya adelantado en el título ${ }^{6}$.

Al tiempo que se parodia el sentimentalismo asociado a la escritura de las mujeres, podemos leer en el poema "Meio termo" de Elizandra Souza una ironía con la escritura didáctica que también suele asociarse a la literatura femenina:

Cansei dessa minha poesia educação

Com pernas cruzadas para não mostrar a calcinha

Dessas palavras cheias de entrelinhas

Que não dizem a que veio, cantadas não entendidas

Esse ar de "mocinha" escondendo a "puta"

Essas caras e bocas que não gritam e nem esperneiam"

(Souza, 2013: 18)

El poema pareciera problematizar la persistencia que vienen teniendo estos estereotipos legitimados por el modernismo, que se volvieron dispositivos de mirada -y de control- respecto de las mismas escritoras mujeres.

Este tipo de relecturas de la tradición letrada que reduce el tono de las "mujeres que escriben" al sentimentalismo o a la escritura didáctica, en la producción de Dinha afecta también al mismo canon. Esta escritora tiene un poema llamado "Vou-me embora para Passárgada" donde claramente parodia el poema de Manuel Bandeira feminizando al yo lírico:

lá sou amiga do rei,

tenho o homem que eu quero

na cama que eu escolherei. (Dinha, 2008:64)

La convencional imagen de la mujer pasiva que espera y que a su vez es objeto del placer del hombre se revierte completamente: la mujer aquí es la poderosa, es la que posee al hombre y es la que toma las riendas del deseo.

En sintonía con esta resignificación de la idea de mujer-pasiva, los textos de Elizandra Souza y de Raquel Almeida -y de muchas escritoras periféricas que se escuchan declamar en los saraus de poesía- acentúan el perfil de la mujer luchadora, representación que en todos los casos permea la lucha de los esclavos y sus formas de resistencia. Dice, por ejemplo, el poema titulado "Sou mulher negra e resisto!":

Contra tudo o que um dia

Me julgou incapaz

Contra o que um dia alegou

Que minha capacidade

Estava na cozinha

Que falou, que minha sina

Sou negra e resito!

6 Este tipo de operaciones que hacen uso de los recursos visuales del poema como el uso del blanco de la pagina es una característica de esta escritora que evidencia una conciencia constante sobre el ejercicio de la escritura al punto tal de llamar a la penúltima parte de su libro "Poemas de poemas" donde encontramos 11 textos que refieren a la práctica de la escritura. 
E graças a minha ancestralidade

De mulheres guerreiras

Tenho em quem me apegar..

(Almeida, 2008:79)

Aquí se aborda otro de los íconos femeninos que estas escritoras se ocupan de resignificar: el de la mujer relegada al ámbito de lo privado que, en el caso de la mujer negra, se vincula no solo a la idea de privacidad espacial sino también a la de estar privada de libertad. El mito de la privacidad asociado a la mujer negra se vincula en este sentido a su condición de sirviente como único destino, modulación que acarrea el mito de la idea utilitarista de la mujer negra. La resignificación estos mitos, como se puede leer en este poema, invoca a una vasta hermandad de mujeres del pasado esclavo para legitimar y autorizar ese posicionamiento de guerrera. Se trata de una operación de historización de aquello que, en tanto "destino" (sina) se percibe como eterno, o, en palabras de Bourdieu, se trata de una "empresa de movilización" que desarma los "mecanismos históricos responsables de la deshistorización y de la eternización relativas a las estructuras de la división sexual" (Bourdieu, 2000: 8). Este tipo de alusiones al pasado esclavo son comunes en estas escritoras y evidencian la necesidad de hacer de sus representaciones un asunto comunitario, su yo lírico pasa a ser un yo plural, desde la lógica del testimonio, esto es un yo representante de un colectivo que tiene un enemigo común a enfrentar y un programa futuro, vinculado en este caso a la toma de conciencia.

Todas estas operaciones de resignificación que analizamos hasta aquí marcan un rasgo distintivo de los textos, que es su naturaleza provocadora, desafiante. Al cuestionar las figuraciones tradicionales de la mujer (negra) periférica, suelen incorporar las percepciones que otros tienen de ellas y, asumiéndolas como reto, las refuncionalizan para su propio provecho.

\section{El canon literario y la mujer negra periférica}

El abordaje de determinados mitos alrededor de la mujer negra periférica, su revisión y reescritura vuelve a traer una problemática al campo literario brasileño que parecía estar saldada en los discursos de las poetas del siglo XXI: la de la revisión de determinados estereotipos alrededor de la mujer considerada como objeto, la mujer reducida al ámbito de lo privado y relegada a la pasividad. Se trata de mitos ya trabajados y resignificados por escritoras como Alejandra Pizarnik, Cecília Meireles, Margo Glantz, Delmira Agustini, Alfonsina Storni, y otras poetas latinoamericanas del siglo XX. Tal y como señala Molloy, la compleja composición que algunas escritoras latinoamericanas llevaron a cabo para reubicarse en el campo literario letrado durante el siglo XX se centró en "un proceso de revisión de figuraciones antiguas o bien inventar figuraciones nuevas que le permitan representar a la mujer como efectivamente no lo hace el modernismo" (Molloy, 2006:71). Esas figuraciones o reconfiguraciones resuenan, como habremos notado, en las producciones de Souza, Almeida y Dinha quienes las retoman y resignifican desde otra perspectiva social y cultural. Esta coincidencia podría llegar a parecer un anacronismo si no tuviéramos en cuenta que las resignificaciones que aquellas poetas se ocuparon de modular parecen no haber considerado la experiencia de las mujeres negras. El nulo abordaje de temáticas de las mujeres negras de las periferias o las referencias estereotipadas a este universo no es exclusivo del siglo pasado. Según las investigaciones llevadas a cabo por Regina Dalcastagnè alrededor de la literatura brasileña contemporánea, la problemática de la mujer negra periférica no es la misma que la de las escritoras blancas de trayectoria letrada y su representación estereotipada sigue sosteniéndose hasta hoy en día: el $80 \%$ de los personajes de la literatura brasileña contemporánea son blancos, y el 7,9 \% son negros; y más aún, "a literatura segrega os negros nos segmentos de menor renda, mais do que ocorre na realidad" (Dalcastagnè, 2008: 93). Además, según los datos de dicha investigación, las principales ocupaciones de los personajes femeninos se concentran en el empleo doméstico y en la prostitución.

En este sentido, podemos afirmar que la producción poética de las escritoras de la periferia no solamente cuestiona el lugar relegado que tiene la mujer en la periferia, sino que, al mismo tiempo, provoca una tensión en relación con el campo literario brasileño, en tanto deja en evidencia de forma indirecta la no problematización de la experiencia de la mujer negra en las producciones firmadas por escritoras de trayectoria letrada.

En relación con el campo literario periférico, por otro lado, la literatura producida por mujeres negras de la periferia también instala una problemática al poner en tensión el uso indiscriminado de la idea de literatura marginal-periférica en tanto un conjunto idéntico en sí mismo. Los diversos recorridos críticos que hemos hecho hasta aqui alrededor de las obras de tres poetas autoidentificadas como negras y periféricas, dan cuenta de la centralidad y complejidad de sus voces: evidentemente, las manifestaciones de las escritoras mujeres de las periferias no son tan simples ni unilaterales como para estudiarlas dentro del conjunto de lo que se entiende por Literatura MarginalPeriférica. Hay un entramado complejo de formas de manifestación y representación del "yo mujer negra periférica" que evidencia la insuficiencia de dicha categoría que tanto la academia como el mismo grupo de escritores de las periferias suelen usar para dar cuenta de estas producciones.

Para reparar las dificultades de visibilidad de las voces de mujeres negras periféricas es necesario deconstruir las categorías atendiendo a la variedad definitoria de estas manifestaciones y hasta el momento no existen artículos académicos enfocados especialmente en la producción periférica femenina (con excepción de una monografía 
de grado -TCC - para la carrera de Periodismo en la UNIP, llevada a cabo por Suevelin Cinti $\left.{ }^{7}\right)$ ¿Cómo constrarrestar las dificultades de visibilidad de las voces de mujeres negras periféricas si no las acompañan siquiera aquellos encargados de deconstruir las categorías que instalan la división de grupos estigmatizados y grupos estigmatizadores? La urgencia de una respuesta a esa pregunta exige que la crítica literaria empiece a subcategorizar la idea de Literatura Marginal Periférica y considere, por ejemplo, la producción de escritoras mujeres de las periferias.

\section{REFERENCIAS BIBLIOGRÁFICAS}

Almeida, R., Duas Gerações. Sobrevivendo no gueto, São Paulo, Toró, 2008

Barthes, R., Mitologías. México, Siglo XXI, 2009.

Bourdieu, P., A dominação Masculina, Barcelona, Anagrama, 2000

Carneiro, S., “Enegrecer o feminismo: a situação da mulher negra na América Latina a partir de uma perspectiva de gênero", in Racismos Contemporâneos, Rio de Janeiro, Takano Editores, 2003

Dalcastagnè, R., “Entre silêncios e estereótipos: relações raciais na literatura brasileira contemporânea", em Estudos de literatura brasileira contemporânea, v. 31, (2008) p. 87-110.

Dinha, De passagem mas não a passeio, São Paulo, Global, 2008

Hall, S., A identidade cultural na pós-modernidade, Rio de Janeiro, DP\&A, 2011

Hapke, I., Erica Peçanha do Nascimento, em Bastos, Dau (et al.), Fórum de Literatura Brasileira Contemporânea, Rio de Janeiro, Torre, 2011, pp.218-226

Kristeva, J., Poderes de la perversión. Ensayos sobre Louis Ferdinand Céline, México DF, Siglo XXI, 2006

Molloy, S., "Identidades textuales femeninas: estrategias de autofiguración", en Mora. Revista del Instituto Interdisciplinario de Estudios de Género, Facultad de Filosofía y Letras, Universidad de Buenos Aires, Nº 12 (Diciembre 2006), pp.68-85.

Peçanha Do Nascimento, É., “É tudo nosso! Produção cultural da periferia paulistana”, Tese de Doutorado, Programa de Pos-graduação da Faculdade de Filosofia, Letras e Ciências Humanas da Universidade de São Paulo, 2011

Souza, E., Punga, São Paulo, Toró, 2007

-, Águas da cabaça, São Paulo, Ed. Do Autor, 2013

Tennina, L., Saraus. Movimiento/Literatura/Periferia/São Paulo, Buenos Aires, Tinta Limón, 2014 Yúdice, G., “Testimonio y concientización”, Revista de Crítica Literaria Latinoamericana, Año XVIII, N³6. Lima (segundo semestre 1992) pp.211-232

7 Agradezco esta información a Érica Peçanha do Nascimento. 